\title{
INSEGURANÇA E PRODUÇÃO DE SUBJETIVIDADE NO BRASIL CONTEMPORÂNEO
}

\author{
Jefferson Cruz Reishoffer \\ Pedro Paulo Gastalho de Bicalho ${ }^{\star \star}$

\section{RESUMo}

O presente artigo objetiva colocar em análise os modos de subjetivação produzidos no Brasil contemporâneo tomando como vetor analítico a questão da insegurança. Utilizaremos o conceito de produção de subjetividade de Guattari e Rolnik, articulando o contexto da insegurança pública, dentro da ordem neoliberal, com as três funções da "subjetividade capitalística" propostas pelos autores: culpabilização, segregação e infantilização. A sensação de insegurança é fortalecida por processos de subjetivação que potencializam a incerteza como principal vetor do controle social e pela repressão a determinados grupos sociais entendidos como "classes perigosas" numa sociedade que busca consolidar o regime democrático.

Palavras-chave: insegurança; produção de subjetividade; risco; controle social.

\section{INSECURITY AND PRODUCTION OF SUBJECTIVITY IN CONTEMPORARY BRAZIL}

\begin{abstract}
The present article aims to put into analysis the subjectification processes that are taking place in contemporary Brazil, using as an analytical vector the unsecurity issue. The Guattari and Rolnik's concept of subjectivity production is used, articulating the context of public insecurity, in the neoliberal order, with the three functions of "capitalistic subjectivity" propounded by the authors: to lay the blame, to segregate and to infantilize. The sensation of insecurity is strengthened by subjectification processes that make the spread of uncertainty the main element of the social control, as well as by the repression of some specific social groups there are seen as "dangerous classes" in a society that works on the consolidation of democracy.

Keywords: insecurity; subjectivity production; danger; social control.

^ Psicólogo, graduado pela Universidade Federal do Rio de Janeiro. Endereço: Universidade Federal do Rio de Janeiro, Instituto de Psicologia. Av. Pasteur, 250 - Pavilhão Nilton Campos - Campus Praia Vermelha - Urca. CEP: 22290-240 - Rio de Janeiro, RJ - Brasil.

E-mail: projefferson@gmail.com

$\star \star$ Doutor, professor da Universidade Federal do Rio de Janeiro. Endereço: Universidade Federal do Rio de Janeiro, Instituto de Psicologia. Av. Pasteur, 250 - Pavilhão Nilton Campos - Campus Praia Vermelha - Urca. CEP: 22290-240 - Rio de Janeiro, RJ - Brasil.

E-mail: ppbicalho@ufrj.br
\end{abstract}




\section{INTRODUÇÃo}

Ao longo da década de 1990 e nos primeiros anos do século XXI, a sociedade brasileira questiona-se sobre a eficácia dos modelos de controle social e as políticas de segurança pública que estão sendo empregadas para o controle da violência urbana e da criminalidade. A questão da violência é estampada nos jornais, enquanto "chacinas, extermínios, linchamentos dos segmentos mais pauperizados passam a ser aplaudidos, apoiados e mesmo incentivados por grandes parcelas da população brasileira" (COIMBRA, 1998, p. 97). Surgem propostas, recuos e reedições de planos passados e é visível e perceptível o avanço da insegurança coletiva e da preocupação social com a chamada criminalidade violenta na cidade.

O objetivo desse artigo é colocar em análise a produção de subjetividade presente no contexto da segurança pública e dos mecanismos de controle social na sociedade brasileira contemporânea, delimitando nossa análise às principais metrópoles brasileiras (Rio de Janeiro e São Paulo), nas quais a questão da criminalidade e da violência possui especificidades que não podem ser generalizadas para todo o país. Para tal estudo, além de buscarmos as principais definições de controle social, procuramos relacionar a questão da escalada da insegurança ao advento de uma nova ordem social: o modelo neoliberal e seus corolários de globalização. Com esta discussão e situando o contexto brasileiro em que emergem determinados modos-de-ser-indivíduo, ${ }^{1}$ utilizamos o conceito de produção de subjetividade de Guattari e Rolnik (2007) e articulamos o contexto da segurança pública com as três funções da subjetividade capitalística ${ }^{2}$ propostas pelos autores: culpabilização, segregação e infantilização. Desta forma, a partir das teorizações sobre a microfísica do poder ${ }^{3}$ de Michel Foucault (2007), entendemos que existem relações de saber-poder atuantes no campo social que não se circunscrevem ao âmbito estatal e que produzem modos de subjetivação em determinados espaços e contextos históricos específicos como estratégias de dominação política e de controle social.

Tal estudo justifica-se para ampliarmos as discussões em torno de segurança pública e de nossas políticas criminais, pois entendemos que não bastará o incremento de medidas técnico-administrativas (aquisição de viaturas, armamentos e contratação de pessoal), enquanto processos de subjetivação fortalecem a insegurança como principal vetor do controle social, clamando pela repressão a determinados grupos sociais entendidos como "classes perigosas" num contexto que busca consolidar um regime democrático (BICALHO, 2005).

\section{Controle e Ordem Social}

Basicamente, podemos definir controle social como uma capacidade que a sociedade busca para se autoregular, de acordo com princípios desejados, a fim de prevenir os conflitos que se originam das interações sociais (COSTA, 2004). A ordem social seria justamente um estágio ideal, sempre perseguido pelas estratégias de controle, em que os conflitos sociais adquiririam certa estabilidade e um baixo nível de ameaça ao status quo. É importante entender que existem variados mecanismos de controle social e várias interpretações do que seria a tão desejada 
ordem social, como veremos mais adiante, e a estabilidade das relações sociais só é adquirida ou interpretada como tal, a partir de configurações sociopolíticas bem determinadas historicamente.

Entre os diversos pensadores do controle social, Thomas Hobbes (15881679) buscou estudar a questão partindo de uma hipotética natureza humana que seria intrinsecamente violenta, sendo necessária a atuação de controles externos a fim de efetivar a vida em sociedade. A famosa frase de que "o homem é o lobo do homem" é a expressão do pensamento hobbesiano de que se o homem fosse entregue a seu próprio arbítrio, num estado sem lei, sem direito, sem constituição política e sem instituições sociais, haveria um estado de guerra de todos contra todos, no qual se caracterizariam o medo, a insegurança e a conflitividade em formas exacerbadas e totais. Hobbes (1651 apud COSTA 2004) acredita que seria necessário impor mecanismos que controlassem a vontade humana, por meio de um Estado-Leviatã que exerceria o controle social através da coerção, onde cada homem sacrifica um pouco de sua liberdade pessoal em nome de um poder absoluto e centralizado que visa assegurar a paz interna e a defesa comum. A violência é dada com critério tanto para o rompimento de um contrato social, firmado entre sujeitos livres e racionais, quanto para o controle exercido pela autoridade política. Contudo, o Estado seria o órgão central do controle social por meio da violência legítima na sociedade, concedida por todo o conjunto de indivíduos que se sacrificam em nome da autoridade política daqueles que representam o Estado, enquanto a violência privada seria o rompimento com a ordem social imposta pelo Estado, pelo enfraquecimento ou falta de eficácia dos mecanismos de controle social. Percebe-se que nesta concepção, a violência é o elemento central da noção de controle social, assim como se destaca a superioridade da influência da sociedade sobre o indivíduo, bem como a centralização no Estado das forças políticas necessárias à ordem social.

Já Norbert Elias (apud COSTA, 2004), apontará a criação de controles internos (autocontrole) que caracterizam as mudanças psicológicas sofridas durante o processo civilizador, seriam mecanismos que iriam prevenir o crime através de medos e temores frente a transgressões do comportamento socialmente aceitável. Estes mecanismos de autocontrole variavam de acordo com a posição e a função de cada indivíduo na sociedade. Dependendo da origem social, cada mecanismo traria sua especificidade na busca de uma coesão social, no respeito às regras de sociedade, na busca de um consenso social. De toda forma, seja pelo controle externo (coercitivo) ou pelo controle interno (autocontrole), Costa (2004, p. 40) dirá que "não há dominação baseada exclusivamente na força, e tampouco existe uma ordem política fundada unicamente no consenso".

O que se percebe é a necessidade do controle social buscar a manutenção e a reprodução de uma determinada ordem social. Há de se pensar e questionar a respeito de que "ordem" estamos falando e de que momentos históricos estamos tratando, isso porque a análise histórica dos saberes que se propuseram a gerir o controle social, está intimamente ligada à proposição de ordem social que deveria ser defendida em tal contexto, pois, caso contrário, tendemos a crer, inocentemente, que qualquer ordem social seria natural e que sua defesa 
se faz indispensável contra quaisquer forças que lhe opõem. Os mecanismos de contra-poder - insurgentes contra a ordem social - cairiam na esfera do desvio, da marginalidade e quaisquer formas de reprimir e neutralizar estas resistências seriam prontamente aceitas como legítimas.

Neste sentido, o pensamento de Michel Foucault será potente em analisar de que forma, para além do exercício do poder Estatal centralizado, existem outros exercícios de poder, no nível micropolítico ${ }^{4}$ por todo o corpo social, definidos não com base na repressão ou na contratualidade, mas como estratégias de produção e reprodução de objetividades e subjetividades em determinados momentos históricos criados para atender a estratégias específicas. Em sua pesquisa dos espaços de confinamento na sociedade moderna, Foucault (1997, p. 118) identificou a emergência da sociedade disciplinar como um conjunto de estratégias de poder que "permitem o controle minucioso das operações do corpo, que asseguram a sujeição constante de suas forças e lhes impõem uma relação de docilidade-utilidade". Docilidade para diminuir os inconvenientes políticos e neutralizar as resistências e utilidade para aumentar sua força econômica por meio do adestramento dos corpos. Dentre as principais características da sociedade disciplinar, podemos destacar: a organização do espaço, como técnica de distribuir os indivíduos inserindo-os em espaços classificatórios e individualizantes; o controle do tempo com o objetivo de produzir o máximo de rapidez e eficácia na execução dos movimentos; e a vigilância ininterrupta que, além de propiciar um controle intenso, permite a produção de um saber sobre os indivíduos (MACHADO, 2007, p. 8). O próprio indivíduo não pode ser considerado como um elemento externo às práticas de poder, como entendia Hobbes (1651 apud COSTA 2004) e nem como um elemento oriundo do processo civilizador, como entendia Elias (apud COSTA, 2004), mas sim como:

[...] realidade fabricada por essa tecnologia específica de poder que se chama disciplina [...] Na verdade o poder produz; ele produz realidade, produz campos de objetos e rituais de verdade. $\mathrm{O}$ indivíduo e o conhecimento que dele se poder ter se originam nessa produção (FOUCAULT, 1997, p. 161).

Seguindo esta localização sócio-histórica e a posição política dos mecanismos de controle social, podemos nos aliar à concepção de Pegoraro (apud DORNELLES, 2003, p. 22) que definirá controle social como uma "estratégia tendente a naturalizar e normalizar uma determinada ordem social construída por força sociais dominantes". Entendendo aqui que não se trata de uma classe social que seria dominante em relação à outra, mas relações de força, vetores de dominação política (que podem estar localizados na diferentes classes sociais e por todo corpo social) que buscam estratégias para manter e reproduzir relações sociais que desejam impor como naturais e normais. É importante destacar tal proposição, pois se verifica que o sistema punitivo, baseado no controle social coercitivo, muitas vezes tende a se concentrar numa ideia de defesa social que garante a tranquilidade e a conveniência de alguns atos, entendidos como nãonocivos à sociedade, em detrimento a outros que são tratados como desviantes, 
marginais, anormais, indesejáveis. É a seletividade do controle social, que definirá que ordem se torna desejável ser defendida, produzindo seus criminosos e seus crimes, e que pode ter como consequência mais temível "a naturalização do conceito de controle social que se tornando aparentemente neutro, vem justificar como normal e natural a desigualdade social, a limitação da liberdade e da autonomia, além da própria seletividade do sistema" (DORNELLES, 2003, p. 24).

A importância de discutir o papel do controle social e sua intrínseca relação com a manutenção de determinadas ordens sociais pode ser melhor destacada em relação às políticas criminais e de segurança pública. Destacamos basicamente duas correntes da Criminologia - Positivista e Crítica - para analisar as relações entre controle social e criminalidade. A Criminologia Positivista busca uma causa explicativa da criminalidade, fundado em um paradigma etiológico, ou seja, tendo por objeto a criminalidade concebida como um fenômeno natural, causalmente determinado, assumindo a tarefa de explicar suas causas segundo o método científico. O crime é entendido como uma realidade em si, como desvio ou enfermidade de uma sociedade estabelecida como "ordem" ou "corpo social". Tanto as definições de ordem, oriunda de uma tradição racionalista, quanto a noção de corpo social, oriunda de uma concepção biológica, entendem o crime como um elemento exterior e nocivo ao funcionamento social, provocando reações imediatas para prever e controlar as atitudes criminais por meio das políticas de controle social, que tanto pelas políticas criminais quanto pela segurança pública centralizam sua atuação em torno da ideia de desviante, daqueles que não se enquadram nos modelos, valores e ideias para manutenção de determinada configuração social (ANDRADE, 1995). Já as correntes da Criminologia Crítica (ao Positivismo), buscam entender o crime como complexidade, como o efeito de uma multiplicidade de atravessamentos (sociais, culturais, políticos, raciais etc.), entendendo que as políticas de controle social definem as condutas desviantes (e não ao contrário, como pensa o Positivismo), por processos de criminalização que caracterizam determinadas classes e sujeitos como criminosos potenciais/virtuais ou como clientela privilegiada do sistema penal, apontando o caráter político e ideológico dos mecanismos de controle social (DORNELLES, 2003).

A tarefa que se coloca é analisar as subjetividades produzidas no campo da segurança pública e das políticas criminais a partir da localização histórica e da contextualização da sociedade brasileira, principalmente das grandes metrópoles. Ao entender a subjetividade como produzida no meio social a partir de elementos heterogêneos, iremos pensar o que os atuais mecanismos de controle social e as políticas de segurança pública, dentro da ordem neoliberal que se impõe, têm produzido. Os crimes, os criminosos e, com efeito, os mecanismos escolhidos para preveni-los ou eliminá-los pertencem a um mesmo campo de imanência, ${ }^{5}$ no qual relações de poder/saber produzem modos de entender o que é crime, quais são os criminosos e que ordem social deverá ser produzida/defendida no contexto brasileiro. 


\section{Democratização, Neoliberalismo e (In)Segurança Pública no Brasil}

A década de 1980 constitui um momento importante para análises que pretendam desenvolver a temática da segurança pública no Brasil. É interessante, e até intrigante, notar que os dois principais marcos políticos deste período - o fim do regime ditatorial e a promulgação da Constituição de 1988 -, que avançam pelo estabelecimento da democracia, não significaram o rompimento com práticas de controle social advindos das Leis de Segurança Nacional e da lógica do "inimigo interno". Vários setores das políticas públicas do país passaram por um amplo processo de mudanças e revisões, mas foi verificado que, mesmo após as diversas transformações decorrentes da Constituição, foram mantidas as estruturas e práticas institucionais ligadas ao passado ditatorial. Segundo Muniz e Zacchi (2004) o quadro institucional das polícias e as divisões de competências entre as mesmas foram preservados, assim como a localização desses setores no pacto federativo mantendo o desenho dado pelo regime militar. Tampouco foram introduzidas novas instâncias de controle e participação social.

Segundo definição da Constituição de 1988, em seu artigo 144, "segurança pública, dever do Estado, direito e responsabilidade de todos, é exercida para a preservação da ordem pública e da incolumidade das pessoas e do patrimônio" (BRASIL, 2008[1988], p.74), tendo como principal órgão executor, a polícia. Cabe aqui o apontamento sobre a necessidade do debate em torno da segurança pública neste momento, pois por definição só há interesse em tal debate quando a ordem que se pretende defender e manter é pública, ou seja, de todos os cidadãos de uma sociedade, que possuem direitos e responsabilidades iguais e que pactuam acordos de convivência comum. Ora, em nosso país é de conhecimento comum nossa tradição autoritária, elitista e desigual, na qual somente no século $\mathrm{XX}$ vivemos cerca de 35 anos de ditaduras ${ }^{6}{ }^{6}$ além da república oligárquica que não garantia a participação política efetiva de grande maioria da população. Em tais regimes não-democráticos não há de se questionar a respeito da ordem pública, pois a ordem que deve ser construída e defendida é de determinados grupos sociais, não de todos. Exemplo disso são as várias definições que a temática da "ordem" veio recebendo em nossa história. As cartas constitucionais anteriores a de 1988 não incorporavam o adjetivo "pública" à ordem que deveria ser defendida e mantida pelas polícias, pois era uma ordem que se confundia com os interesses das forças sociais dominantes de então, principalmente do das oligarquias e do Estado. A ordem dita "pública" somente irá ganhar força de lei a partir do momento em que a democracia busca se estabelecer como regime político. Desse modo, a ordem social deve ser efetivada com vistas na garantia dos direitos individuais de todos e na participação política dos cidadãos. Contudo, as práticas que irão assegurar a manutenção da ordem pública não sofreram nenhum tipo de mudança. Muniz (2001, p. 194) comentando a respeito da função das polícias militares instituídas em lei, dirá:

As cartas constitucionais republicanas anteriores a 1988, não deixam dúvidas quanto à principal função das PMs. Tratavase, primeiro, de salvaguardar a "Segurança Nacional" 
mobilizando seus esforços para a "segurança interna e manutenção da ordem" do Estado. Não é difícil concluir que o que estava em jogo era, fundamentalmente, a sustentação de uma lógica que pressupunha o "Estado contra a sociedade", ou melhor, uma concepção autoritária da ordem pública que excluía os cidadãos de sua produção, uma vez que eles eram percebidos como "inimigos internos do regime" que "ameaçavam a tranquilidade e a paz pública.

Com o processo de redemocratização em andamento, no início dos anos 1980, os principais veículos de comunicação passam a denunciar o aumento da violência urbana e a necessidade o recrudescimento das políticas de segurança nas principais metrópoles brasileiras que, paradoxalmente, haviam elegido governos de oposição em plena transição democrática, ${ }^{7}$ baseados em princípios condizentes à garantia dos direitos humanos. Dornelles (2003) irá caracterizar dois modelos de segurança pública empregadas no período pós-ditaduras, que, desde 1983, têm sido implementados alternadamente: o modelo do eficientismo penal e o modelo da garantismo constitucional. O primeiro, marcado pelo discurso da "lei e ordem" e pela militarização das práticas policiais, na qual se destaca o uso da força por meio de ações repressivas diretas e até o uso de ações ilegais e de práticas de terror, que nada deixam a dever à época ditatorial. O segundo baseia-se no discurso da cidadania, buscando articular medidas imediatas com planejamentos de longo prazo, visando conter o crime com estratégias não-repressivas que importem a articulação de políticas públicas de diferente naturezas, buscando controlar a criminalidade e a violência sem perder os princípios democráticos como diretriz.

De forma hegemônica, a aumento da criminalidade passou a ser associado à adoção de práticas menos repressivas com o fim do regime ditatorial. Os conflitos sociais passaram a ser qualificados como "guerra civil" e exigiu-se cada vez mais a militarização das forças de segurança contra os "bandidos e criminosos" (COIMBRA, 2001). Esta concepção de "guerra", que fortaleceu a militarização da política de segurança pública, "vem do período da ditadura militar onde o opositor político era o inimigo. Os bandidos de toda espécie, nesta concepção de segurança pública, são também percebidos como inimigos e não apenas como suspeitos" (COIMBRA, 2001, p. 5). O perigo, neste momento, é traçar uma equivalência entre a adoção de regimes democráticos com a escalada de insegurança e violência em nosso país. Percebemos que, em alguns debates públicos, a democracia é questionada pela tentativa de garantir que os principais direitos individuais sejam respeitados tendo como princípio norteador os Direitos Humanos, confundido tal intento com a proteção de criminosos, gerando, em certos setores sociais, uma espécie de saudosismo dos tempos de ditadura. Bicalho (2005) ao cartografar ${ }^{8}$ as concepções de direitos humanos presentes nas falas de policiais militares do Rio de Janeiro, verifica que os policiais pensam o humano como "aquele que não é o vagabundo"9 Dessa forma, além de constatar a ideia de que os Direitos Humanos seriam um ente disposto a defender os direitos dos criminosos, são interpretados "como uma via de deses- 
tabilização de políticas de segurança pública, tendo vista que impedem muita vezes, o 'livre exercício' da atividade policial [...] uma maneira da polícia não poder trabalhar 'à vontade"” (BICALHO, 2005, p. 128).

Devemos, então, entender que os anos 1980 não ficaram caracterizados apenas como o início do processo de democratização do Estado Brasileiro mas, sobretudo, começava a se impor uma nova ordem socioeconômica em termos mundiais: o modelo neoliberal. Tal ordem socioeconômica irá se construir sobre a liberdade dos mercados, o aumento da produtividade com a flexibilização e a precarização das relações de trabalho e com o acúmulo do capital em larga escala. A concentração do capital viabiliza-se pela globalização das instituições bancárias e financeiras, pelo emprego de novas tecnologias para intensificar as operações globais e pela utilização de tecnologias avançadas de comunicação que potencializam o capital produtivo. O neoliberalismo, com seu corolário de globalização, passa a impor novas relações de consumo e produção, acompanhadas da debilitação dos direitos econômicos, sociais e culturais, principalmente dos direitos coletivos das classes trabalhadoras, do aumento do desemprego com a implantação de mecanismos de aumento da produtividade. As proteções sociais perdem espaço para acumulação acentuada do capital e para o consumismo sem limites. Segundo Dornelles (2003, p. 27), “o Estado abandona seu papel de composição e de arbitragem, passando para o mercado a regulação social. A ciência econômica passa a ser o centro da teoria social [...]". O Estado passa a eliminar os sistemas de proteção social, controlando os gastos públicos e não intervindo na economia.

A partir do fortalecimento da lógica neoliberal de consumo, as questões econômicas e sociais perdem a intervenção estatal, saem dos programas de manutenção da ordem pública, instaurando-se a insegurança coletiva, pois aqueles que já não dispunham das mínimas garantias de sobrevivência, agora irão compor a imensa lista de desempregados e excluídos. A ordem pública passa a se confundir com o controle da criminalidade, com a neutralização daqueles que colocam em risco o sossego dos consumidores, principais personagens da nova ordem. Nas palavras de Batista (2002, p. 61):

Com a retirada do poder da política, essa ansiedade difusa e dispersa é deslocada para um único elemento: a segurança. Nos jornais, as páginas de política se convertem em páginas de polícia. Esse campo dá visibilidade, dilui a incerteza, mas ao mesmo tempo divide, semeia a desconfiança mútua, isola e dispersa.

É importante considerar que o aumento da insegurança e o medo da criminalidade urbana ajudam no crescimento das empresas de segurança privada, com mão-de-obra especializada e sistemas eletrônicos de segurança de última geração. Os vigilantes privados em atividade no país superam em cerca de 5\% o total de policiais militares de todos os estados brasileiros. Segundo dados da Coordenação de Controle da Segurança Privada da Polícia Federal, existem hoje no país 431.600 vigilantes, ou seja, 19.700 a mais do que os 411.900 policiais militares estimados pelo Ministério da Justiça. Com 139.800 homens, o estado com 
maior número de vigilantes privados é São Paulo, que também concentra o maior número de policiais militares (cerca de $80 \mathrm{mil}$ ). De acordo com o relatório da Polícia Federal, o Rio de Janeiro é o segundo colocado, com 45.600 homens atuando na segurança privada (ABDALA, 2008). Isso considerando os dados oficiais produzidos pelos órgãos de segurança pública, deixando de fora todos os profissionais que exercem segurança informal e inúmeros policiais que exercem a atividade de segurança como "bico". ${ }^{10}$ Paralelo a isso, constata-se a adoção de novas estratégias de proteção espacial, com o aumento dos muros, a instalação de câmeras e circuitos internos e até cercas elétricas. Nos bairros mais nobres do Rio de Janeiro constroem-se novos padrões de segregação social com a vida dos condomínios, estabelecem que aqueles considerados como "diferentes" dos padrões desejados mantenham-se afastados, consolidando a separação e a restrição dos movimentos (DORNELLES, 2003). De acordo com as palavras de Baptista (1999, p. 38):

$\mathrm{O}$ apartheid carioca impede o bairro, espaço onde diferentes subjetividades e classes sociais circulam e atravessam suas ruas e esquinas desprotegendo e inquietando o nirvânico equilíbrio burguês [...] A vida condominizada, vendida no mercado como prazer, conforto e segurança, tem sauna, piscina, amigos iguais, proteção para as crianças, vizinhos iguais, corpos iguais, computador, necessidades iguais [...].

A instalação da insegurança coletiva passa a impedir as ações coletivas, fazendo crescer o individualismo, a competitividade e a desconfiança do outro. Dirá Bauman (2000, p. 13): "as pessoas que se sentem inseguras, preocupadas com o que lhes reserva o futuro e temendo pela própria incolumidade não podem realmente assumir o risco que a ação coletiva exige". Ainda para o autor:

[...] o mais sinistro e doloroso dos problemas contemporâneos pode ser melhor entendido pela rubrica Usincherheit, termo alemão que funde experiências para as quais as outras línguas podem exigir mais palavras - incerteza, insegurança e falta de garantia (BAUMAN, 2000, p. 13).

Assim, a dispersão da insegurança faz com que o espaço público seja construído pelo discurso do medo, no qual as relações sociais são dominadas pela desconfiança e pela permanente disputa entre iguais. Exemplo disso é a análise empreendida por Robert Castel (2005) que aponta que a solidariedade dos estatutos profissionais transformou-se em concorrência entre iguais e foi necessário evidenciar as diferenças para manter ou melhorar a condição de trabalho. Ao mesmo tempo em que há uma individualização das tarefas e trajetórias profissionais há também uma responsabilização dos sujeitos: cabe a cada um encarregarse de si mesmo, em permanente competição com colegas de profissão e cumprir a intimação de ser bem-sucedido, sob a ameaça permanente do desemprego. Produz-se a subjetividade que "apaga a memória e a consciência de classe, onde o trabalhador assalariado substitui a consciência coletiva pelo agradecimento de estar inserido no mercado" (DORNELLES, 2003, p. 29). 
Dessa forma, está preparado o campo para a assunção de bodes expiatórios das incertezas e inseguranças de toda população. Novos mecanismos de controle social são gestados e aumentam os argumentos que defendem a violação dos direitos humanos para os setores mais vulneráveis da população. Justamente estes que, por incapacidade de consumo e pela pouca possibilidade de inserção no mercado, passam a ser alvo das políticas repressivas de controle social e de segurança pública: os negros, os pobres e os imigrantes indesejáveis. A resposta ao problema da criminalidade passa a concentrar nos crimes e nos criminosos, identificados e naturalizados como produto de classes sociais ou da pobreza, em vez de se concentrarem nas lógicas de criminalização e na ordem social (desigual, injusta e excludente) que deseja se instalar com necessária. Desta forma:

O clima difuso de insegurança e vulnerabilidade obscurece o mapeamento do problema para oferecer respostas compatíveis com os valores da democracia e dos direitos fundamentais, uma vez que as questões da esfera pública tendem a se deslocar cada vez mais para o âmbito do direito penal, cuja solução (repressora e simbólica) induz o mal que pretende curar (ARGÜELLO, 2009, p. 5-6).

Percebe-se que a ordem social não é caracterizada como a efetiva consolidação das mínimas condições de cidadania para todos, mas sim, como defesa do direito de consumo de alguns. É o que Wacquant (2001, p. 7) denominou como "a remediação de um 'mais Estado' policial e penal a um 'menos Estado' econômico e social", e ainda completou que tal penalidade neoliberal é ainda mais funesta em países atingidos por fortes desigualdades de condições de vida e desprovidos de tradição democrática. É quando as questões sociais se tornam questões de polícia. Os "inimigos" da ordem são estes que ousam transpor as barreiras do consumo e estão continuadamente expostos à violência policial. Tal violência é inserida numa tradição nacional secular de controle dos miseráveis pela força, tradição oriunda da escravidão e dos conflitos agrários, que foram fortalecidos por duas décadas durante a ditadura militar, na qual a luta contra a "subversão interna" era disfarçada em repressão aos opositores do regime (WACQUANT, 2001).

O controle social, por meio do Estado Penal, também adota as lógicas da "guerra" e do "inimigo interno" em defesa da ordem estabelecida, que deve ser a ordem do consumo e do mercado. Diante disso, também apoiados por uma criminologia de cunho positivista, que buscou identificar de forma objetiva e asséptica biologicamente, os negros, ou socialmente, os pobres, como potenciais delinquentes; a figura do jovem, negro e pobre aparece como a figura atual da ameaça. Batista (2005, p. 42) aponta os entrelaçamentos de lógicas presentes em diferentes períodos da história brasileira e a presença de um discurso criminológico que criminaliza as desigualdades e a pobreza, a partir de critérios morais:

[...] analisando os processos entre 1968 e 1988, a partir de certa visão sobre drogas introduzidas pela vitória da política norte-americana e pela ideologia da Segurança Nacional, pude perceber as permanências das metáforas biológicas, 
do social-darwinismo, do determinismo, do olhar moral e periculosista que sobreviveram imunes ao longo do século: são as famílias desestruturadas, as atitudes suspeitas, o meio ambiente pernicioso à sua formação moral e outras pérolas que pontificavam e que alimentaram o gigantesco processo de criminalização da juventude pobre que ali se iniciava, com a consagração da nossa política criminal com derramamento de sangue.

É nessas bases autoritárias que nossa sociedade busca recuperar sua formação democrática. São práticas que reafirmam preconceitos positivistas de ordenamento social, que tornam alvo de um seletivo aparelho penal apenas aqueles que estão abaixo da potencialidade consumista ou que não adquiriram reais possibilidades para efetivação da cidadania. O recorte é feito e o olhar da repressão é recrudescido para os crimes que atentam contra o patrimônio e que se referem ao varejo da drogas. Sob o manto do "flagelo das drogas", têm-se empreendido em larga escala a criminalização das populações que moram nas favelas, identificadas como o principal foco do tráfico de drogas e difusoras da violência. Identifica-se o comércio varejista das favelas como o principal responsável pela violência na cidade (RIBEIRO; DIAS; CARVALHO, 2008). Assim, mesmo com a atuação de grupos sociais organizados que reivindicavam a reconstituição de uma democracia e a adoção de dispositivos na Constituição de 1988 que pudessem assegurar o respeito aos direitos humanos e da cidadania a diversos grupos excluídos, foi mantida a atribuição a determinados grupos - e agora não mais aos comunistas como nos tempos de ditadura, mas aos jovens pobres das periferias - caracterizados como perigosos, marginais, infratores, como se tais características fossem de sua natureza (ARANTES, 2004). Tal "natureza" viria justificar a adoção de medidas extremadas de controle social e repressão destes que entendidos como "classes perigosas" dentro de uma sociedade democrática. Nas palavras de Bicalho (2009, p. A15):

Perigosas porque pobres, por desafiarem as políticas de controle social no meio urbano e, deste modo, mobilizam os mais diferentes setores da sociedade, como a família, a escola, o trabalho e a polícia, que indicam e orientam como todos deveriam se comportar, trabalhar, viver e morrer. [...] A modernidade exige cidades limpas, assépticas, onde a miséria - já que não pode mais ser escondida e/ou administrada deve ser eliminada. Eliminação não por sua superação, mas pelo extermínio daqueles que a expõem incomodando os 'olhos, ouvidos e narizes' das classes mais abastadas.

\section{Produção de subJetividade e insegurança}

De início, entendemos que abordar a questão da subjetividade a partir do campo social pode gerar uma série de controvérsias e mal-entendidos. Ao dizermos que "o homem é um ser social" ou que o indivíduo vive em sociedade e é 
por ela influenciado, podemos ser capturados pela tradição da Filosofia Cartesiana que definiu o sujeito como "coisa pensante" que habita um corpo, estando separado da exterioridade. Como destaca Ferreira Neto (2004, p. 113) esta é "uma perspectiva que tem por solo a oposição entre interno e externo, no qual a subjetividade é entendida como interioridade". Ou seja, desejamos abordar a questão da subjetividade não por uma relação causal em que a subjetividade é influenciada pela sociedade e nem que a sociedade é constituída pelo agrupamento de várias subjetividades individuais, mas sim com a concepção que propõe:

\begin{abstract}
A subjetividade entendida como emergência histórica de processos, não determinados pelo social, mas em conexão com processos sociais, culturais, econômicos, tecnológicos, midiáticos, ecológicos, urbanos, que participam de sua constituição e de seu funcionamento. (FERREIRA NETO, 2004, p. 114)
\end{abstract}

A problemática da subjetividade será aqui abordada a partir da concepção de Deleuze e Guattari que tem "como característica distintiva sua indissociabilidade da idéia de produção. [...] como produção de formas de viver, de sentir, de conhecer" (KASTRUP, 2000, p. 20). A produção de subjetividade, assim como da objetividade, provém de um campo de forças ou fluxos heterogêneos, sempre em movimento, que se agenciam produzindo sujeitos e objetos em um contínuo processo de produção. Esse plano das forças e seus agenciamentos são a expressão do que Deleuze denominou rizoma, que pode se definido como "um campo coletivo de forças/fluxos dispersos, múltiplos e heterogêneos. [...]Todas as formas existentes e visíveis resultam de um agenciamento destes fluxos heterogêneos" (KASTRUP, 2000, p. 21). Desta forma, pensaremos a subjetividade como processo, em incessante produção por todo corpo social a partir de elementos heterogêneos, e não como estrutura identitária ou interioridade. Assim, tomaremos a temática da (in)segurança pública como um dos vetores passíveis de se cartografar a produção de subjetividades contemporânea, entendendo que tal produção não se inicia, termina ou mesmo se determina a partir desse ponto.

Guattari e Rolnik (2007) propõem que as forças sociais que administram o capitalismo hoje entenderam que a produção de subjetividade talvez seja mais importante do que qualquer outro tipo de produção. O capitalismo atual não atua apenas no campo da economia política, mas principalmente no campo da economia subjetiva, pois a ideia de produção de subjetividades está além da circunscrição do alvo da luta à reapropriação dos meios de produção ou dos meios de expressão política. Os autores denominam "produção de subjetividade capitalística", a produção em larga escala de modos de pensar, sentir e atuar no mundo em escala mundial. São formas de expressão dominantes que produzem sujeitos serializados, normatizados, modelizados de acordo com os padrões dominantes, opondo a estas máquinas produtoras de subjetividade "modos de subjetivação singulares" ou "processos de singularização" que são "uma maneira de recusar todos esses modos de codificação preestabelecidos, recusá-los para construir modos de sen- 
sibilidade, modos de criatividades quem produzam uma subjetividade singular." (GUATTARI; ROLNIK, 2007, p. 22). Entendemos então que nossos sentimentos, pensamentos e comportamentos não são produtos de uma interioridade psíquica e nem existem no mundo em si; eles são fundamentalmente produzidos a partir de práticas historicamente localizáveis, e a tarefa que se impõe neste momento do trabalho é debater algumas das principais características da subjetividade capitalística produzida no campo da segurança pública, mais especificamente no nosso contex to brasileiro que, como foi anteriormente debatido, questiona a eficácia dos atuais mecanismos de controle social em prover segurança a todos.

A própria insegurança, que parece ser um vetor dominante na economia subjetiva atual, é forjada dentro de um contexto histórico bem determinado. Castel (2005, p. 9) afirma que as sociedades modernas são construídas sobre o terreno da insegurança, "porque são sociedades de indivíduos que não encontram, nem em si mesmo, nem em seu entorno imediato, a capacidade de assegurar proteção". O autor dirá que o sentimento de insegurança é produzido por meio da promoção do indivíduo como centralidade da modernidade, segundo uma expectativa socialmente construída de proteções e as capacidades efetivas dessa sociedade em praticá-las.

Em uma análise contundente, o autor buscou estudar os sistemas de proteção que, na história do liberalismo, buscaram compensar as inseguranças que poderiam atingir o indivíduo. Mostra que enquanto o Estado assumiu a proteção social aos indivíduos que não tinham condições econômicas, culturais e sociais de se proteger dos imprevistos da vida, ele naturalizava-se como suporte do indivíduo na sociedade. Com o advento do capitalismo globalizado tal proteção social dá lugar à liberdade do mercado e o indivíduo é entregue à sua própria capacidade em se assegurar (CASTEL, 2005). Além das proteções estatais, aqueles que ainda conseguiam um emprego formal contavam com redes de apoios coletivos (sindicatos, partidos políticos, leis trabalhistas) que garantiam certa estabilidade frente ao desemprego. Com a precarização das relações trabalhistas, diminuição dos postos de trabalho e o aumento do trabalho informal e da dupla jornada, os trabalhadores perdem as proteções coletivas e se tornam únicos responsáveis pela disputa em um mercado competitivo e flexível, individualizados em sua conquista de segurança. Aqueles que antes eram companheiros de trabalho tornam-se seus principais rivais na corrida pelo emprego.

Os efeitos sociopolíticos desta privatização das práticas de segurança produzem o que Castel (2005) denominou "descoletivização do indivíduo", pois um dos grandes fatores de insegurança é que, cada vez mais, uma massa de indivíduos são "convencidos" que estão "soltos" no mundo capitalista, devendo garantir sua proteção social numa sociedade que nunca garantiu a igualdade dos direitos. Alguns poucos que possuem condições ainda recorrerão a seguros privados que serão múltiplos numa sociedade das incertezas - seguro de casa, de vida, de carro, segurança privada, segurança alimentar, segurança etc. - e que, potencialmente, sobrevivem da própria insegurança que dizem evitar; mas outros serão simplesmente excluídos entregues a toda sorte de destino. Na conclusão de Castel (2005, p. 65-66): 
Existe uma relação estreita entre a explosão dos riscos, a hiperindividualização das práticas e a privatização dos seguros. Se os riscos se multiplicam ao infinito e se o indivíduo está só para enfrentá-los, cabe ao indivíduo privado, privatizado, fazer seu próprio seguro, se ele pode. Por conseguinte, o controle de riscos não é mais um empreendimento coletivo, mas uma estratégia individual, enquanto que o futuro dos seguros privados é garantido através da multiplicação dos riscos.

A produção da insegurança nas subjetividades contemporâneas é eficaz ao substituir os possíveis atravessamentos sociopolíticos por indivíduos/segmentos da própria sociedade que serão alvo de perseguição e repressão por parte do controle social repressivo. Assim, a partir do vetor da insegurança, podemos destacar algumas das principais características da subjetividade contemporânea no Brasil. Entendemos que estas características apontadas, a partir das teorizações de Guattari e Rolnik (2007) sobre as funções da subjetividade capitalística, encontram-se entrecruzadas, agenciadas de certa forma compondo uma subjetividade dominante, mas aqui serão desmembradas apenas com o intuito de se tornar claro ao leitor.

Assim, é sempre relevante (re)lembrar os jogos políticos e os processos de subjetividade que se fizeram presentes durante a vigência da Doutrina de Segurança Nacional em nome da "segurança do regime" que não podia tolerar os "antagonismos internos". Toda e qualquer oposição que pudesse abalar esta segurança deveria ser punida, assim como os "diferentes" eram percebidos como inimigos da pátria e deveriam, por isso, ser evitados, calados, exterminados. Os inimigos do regime, principal alvo da política de segurança, eram principalmente os comunistas, mas também se estendiam às classes populares e a todos aqueles que não se enquadravam nos projetos de ascensão social que deveriam ser fortalecidos pelo modelo do "milagre econômico" em detrimento da participação nas decisões políticas do país. A família torna-se principal alvo das máquinas sociais produtoras de subjetividades, pois seria dentro de seu ambiente estruturado que deveria ser iniciada a prevenção contra os inimigos da pátria. Os filhos “desviantes" seriam aqueles que questionavam o sistema, não estavam adequados aos padrões de subjetividade propostos e, portanto, eram eleitos inimigos da ordem social. Serão reforçados, dessa forma, modelos individualizantes de família e de homem, nos quais este deveria voltar-se para si mesmo e negar qualquer participação coletiva, com a privacidade e o intimismo fortalecidos como os domínios seguros contra os perigos do mundo (COIMBRA, 1995a).

Portanto, para os filhos desviantes e para a família desestruturada, um exército de especialistas do psiquismo será convocado. Estes, comprometidos com a manutenção da ordem e com o restabelecimento de subjetividades que ousavam se singularizar, que desejavam outros territórios subjetivos que não os socialmente propostos, remeterão ao privado e ao intimismo toda motivação de confronto com a ordem estabelecida. Essas práticas, legitimadas como científicas - portanto, neutras -, "psicologizavam" o político, naturalizavam formas de ser e estar no mundo, fazendo com que se acreditasse que os des- 
viantes necessitavam de tratamento (psicológico ou moral, ou ambos) e, caso continuassem a negar os modelos dominantes, deveriam ser neutralizados para a segurança da ordem. (COIMBRA, 1995a).

No Brasil contemporâneo, a individualização das questões e a despolitização do social apresentam-se, ainda, como a principal característica subjetiva. Perante a institucionalização de subjetividades individualizadas, qualquer ato que contrarie a ordem vigente é interpretado como revolta individual contra um direito particular, (patrimônio, vida, liberdade) trazendo como consequência o afastamento dos espaços públicos e a delegação da resolução dos problemas sociais e políticos para o poder estatal. Por outro lado, caberá ao próprio indivíduo adotar medidas de segurança privadas, que estarão à disposição do consumidor - tais como segurança privada, câmeras, cercas elétricas - até a escolha por determinados espaços e comportamentos não entendidos como perigosos. Acreditamos que esta é uma das variantes do que Guattari e Rolnik (2007) apontam como uma das funções da subjetividade capitalística, a culpabilização. Cabe a nós como indivíduos na ordem neoliberal "a assumir a singularidade de nossa própria posição como o máximo de consistência" (GUATTARI; ROLNIK, 2007, p. 49).

Outra importante característica é a infantilização das subjetividades. Segundo Guattari e Rolnik (2007, p. 50):

Pensam por nós, organizam por nós a produção e a vida social. Além disso, consideram que tudo o que tem a ver com coisas extraordinárias - por exemplo, o fato de falar e viver, o fato de ter que envelhecer, de ter que morrer - não deve perturbar nossa harmonia no local de trabalho e nos postos de controle social que ocupamos, a começar pelo controle social que exercemos sobre nós mesmos. A infantilização - por exemplo, das mulheres, dos loucos, de certos setores sociais, ou de qualquer comportamento dissidente - consiste em que tudo que se faz, se pensa ou se possa vir a fazer ou pensar seja mediado pelo Estado.

Este conceito possui intima conexão com o que Foucault (2007) nomeou com a "destituição dos saberes locais" em nome de regimes de verdade constituídos por relações de poder. Os saberes destituídos, ou dominados nas palavras do autor, são "conteúdos históricos que foram sepultados, desqualificados, mascarados em coerências funcionais ou em sistematizações formais" (FOUCAULT, 2007, p. 170). São os saberes das pessoas que são dominados por regimes de verdade que se pretendem universais e objetivos, que serão interpretados e pronunciados pelos "especialistas". Faz parte da precarização das relações de trabalho e da efetividade dos controles atuais, a contínua especialização de tudo, produzindo o sentimento de que nunca sabemos o suficiente para gerir nossas vidas e garantir nosso futuro, aumentando a insegurança. Afinal, estar "desinformado" na sociedade da informação é motivo de angústia e até exclusão. 
E a terceira característica - apostamos na ideia da mais relevante para entendermos a produção de subjetividade no campo da segurança pública - é a segregação. Vinculada diretamente à culpabilização, ela identifica qualquer processo com quadros de referências imaginários, propiciando diversas formas de manipulação. É a atribuição a alguns indivíduos/segmentos sociais da responsabilização pelo clima de insegurança coletiva e de medo. São selecionados alguns crimes, principalmente os ligados ao patrimônio e ao tráfico de drogas como produtores da violência social, e são desqualificados outros, como o de "colarinho branco", por exemplo, como desprovidos de qualquer nocividade para a situação atual. "É como se para se manter a ordem social tivesse que se instaurar, ainda que da maneira mais artificial possível, sistemas de hierarquia inconsciente, sistemas de escala de valor e sistemas de disciplinarização" (GUATTARI; ROLNIK, 2007, p. 50).

Ora, se o espaço público é construído sob o discurso do medo e da incerteza, Bauman (2000, p. 23) nos diz que a solução é encontrar um inimigo interno e "unir forças num ato de atrocidade comunitária". O que não pode acontecer é que alguém não queira "participar do clamor público e cuja recusa lance dúvidas sobre a correção e justeza do ato" (BAUMAN, 2000, p. 23). Se os inimigos da pátria eram os comunistas, principais ameaças políticas na ditadura; hoje, dentro da nova ordem mundial, os novos "inimigos" são os segmentos mais pauperizados, "aqueles que os mantenedores da ordem consideram suspeitos, 'perigosos' e que devem, portanto, não somente serem evitados, mas eliminados" (COIMBRA, 1995b). As subjetividades dominantes permitirão a suspensão dos princípios éticos, dos direitos constitucionais e das garantias legais, comprometendo as bases democráticas das sociedades ocidentais (DORNELLES, 2003, p. 165). São processos, já presentes nos tempos ditatoriais que legitimam os procedimentos de exclusão, de não reconhecimento dos direitos, da ameaça da diferença, da construção dos não-humanos e não cidadãos. Assim:

A estratégia não foi de criminalizar o pobre pura e simplesmente, mas de associar o local onde ele habita ao terror imposto por um novo e moderníssimo grupo de selvagens, assassinos cruéis e sanguinários: os traficantes de drogas. A figura do traficante nessas localidades é o que permite que se exerça essa política de invasão e de extermínio, mesmo quando se sabe que ali funciona apenas uma parte do tráfico. (BIAR, 2007 apud RIBEIRO; DIAS; CARVALHO, 2008, p. 8)

\section{Considerações Finais}

A busca pela efetividade do regime democrático ainda não se consolidou. Mesmo que a estrutura político-social busque a consolidação das formas democráticas, a garantia dos direitos individuais e coletivos e a cooperação social na resolução dos principais problemas advindos da desigualdade social, os principais processos de subjetivação, da produção dominante de subjetividades, atualmente, primam pela individualização das questões, para a culpabilização dos setores po- 
pulares pela violência urbana e pela aprovação do extermínio e da barbárie como métodos de repressão aos crimes associados à pobreza. É neste sentido que, mais uma vez, Guattari e Rolnik (2007, p. 157-158) nos advertem:

A democracia talvez se expresse em nível das grandes organizações políticas e sociais, mas ela só se consolida, só ganha consistência se existir no nível da subjetividade dos indivíduos e dos grupos [...] a questão é justamente colocar a micropolítica por toda parte - em nossas relações estereotipadas de vida pessoal, de vida conjugal, de vida amorosa, e de vida profissional, nas quais tudo é guiado por códigos. Trata-se de fazer entrar em todos esses campos um novo tipo de pragmática: um novo tipo de análise que corresponderia de fato um novo tipo de política.

Acreditamos que com essas considerações, entenderemos que não basta buscarmos leis e técnicas que preguem pela defesa da democracia, se ao nível micropolítico os modelos de subjetivação conservadores e dominantes nos capturam de todos os lados, judicializando o cotidiano, individualizando as questões e criando políticas autoritárias dentro de uma sociedade democrática que deveria possibilitar, simultaneamente, a diversidade de expressões subjetivas e a igualdade de condições sociais. Sob o discurso da insegurança, o espaço público e as criações coletivas perdem força, dando lugar a subjetividades individualizadas que buscam expurgar a insegurança, elegendo alguns setores sociais e não a dinâmica social como um todo. Contudo, é importante que se destaque que a composição dessas subjetividades capitalísticas não são necessárias ou eternas, por serem construídas dentro de um contexto sócio-histórico, por isso mesmo, podem ser superadas, questionadas, rejeitadas, para a potencialização de processos de singularização que rompem com estes modelos dominantes de subjetivação. Tal mapeamento das estratégias de resistências ainda que mereçam um trabalho de análise posterior, devem-se inscrever cotidianamente em nossas práticas. Concluindo com Baptista (1999, p. 38-39):

Nos condomínios da classe média, a segurança e a privacidade caminham juntas com o apartheid. Privacidades paranóicas que temem perder as referências de classe, que temem negros, trabalhadores braçais e a diferença. A vida condominizada solicita limites e barreiras a todo o momento que não só segregam, mas solidificam e afirmam a construção de identidades [...] Ao apresentarmos esta maquinaria de subjetividade, sugerimos a atenção para a eficácia desse dispositivo político de intimização de vida, em que o déspota não é tão visível; sugerimos a descentralização do olhar fixo em uma categoria de humano sem práticas, desmaterializado e onipotente; sugeríamos a atenção para a inventividade capitalista na fabricação de maquinarias que podem ser usadas, desmontadas ou destruídas[...]. 


\section{Notas}

${ }^{1}$ Os modos-de-ser-indivíduo podem ser entendidos como formas de pensar, sentir e se comportar no mundo que são essencialmente produzidas em um determinado momento histórico e que são adotadas como formas de se subjetivar dentro de um contexto social específico.

${ }^{2}$ O termo "capitalística" foi forjado por Félix Guattari (GUATTARI; ROLNIK, 2007) para designar um modo de subjetivação que não se encontrava apenas ligado às sociedades ditas capitalistas, mas que caracterizava também as sociedades ditas socialistas, até aquele momento nos anos 1970, bem como as dos países de Terceiro Mundo, já que todas viveriam numa espécie de dependência e contradependência do modelo capitalista.

${ }^{3}$ Segundo Machado (2007), microfísica do poder significa tanto um deslocamento do espaço de análise das relações de poder quanto do nível em que estas se efetuam. É dirigir a atenção para as formas locais e específicas das malhas do poder que exercem um controle minucioso do corpo.

${ }^{4}$ Segundo Baptista (1999, p. 37), "micropolítica não no sentido de uma política menos secundária, mas como campo de ação em que objetividade/subjetividade, poder/saber, público/privado, desejo/ criação, indivíduo/sociedade, trabalho/vida, dicotomias criadas e articuladas historicamente são interpeladas junto às formas estabelecidas de se fazer política".

${ }^{5}$ Sobre campo de imanência Deleuze e Parnet (1998) fazem referência ao plano onde o desejo é construído, afastando-nos de qualquer preexistência subjetiva ou objetal, transformando as produções desejantes em um processo que se desenvolve em um plano em que há apenas partículas e fluxos heterogêneos que, quando combinados e agenciados, dão contornos às formas desejantes, aos sujeitos e aos objetos. Segundo os autores: “O desejo não é, portanto, interior a um sujeito, tampouco tende para um objeto: é, estritamente, imanente a um plano ao qual ele não preexiste, a um plano que precisa ser construído, onde partículas se emitem, fluxos se conjugam." (DELEUZE; PARNET, 1998, p.105).

${ }^{6}$ O Estado Novo de Getúlio Vargas (1937-1945) e a Ditadura Militar (1964-1985).

${ }^{7}$ Referimo-nos às vitórias de Leonel Brizola no Rio de Janeiro, Franco Montoro em São Paulo e Tancredo Neves em Minas Gerais.

${ }^{8}$ Segundo Bicalho (2005, p.106): “A cartografia constitui uma proposta metodológica que visa acompanhar um processo e que se propõe a pôr em análise o modo pelo qual vão emergir as formas hegemônicas e individuadas da rede, esta sempre marcada pela heterogeneidade. Os vetores que constituem as subjetividades, pensados desta forma, não estão no mundo, não são objetivos, como também não estão no sujeito. São forças sempre em movimento que emergem sob uma amarração temporária [...]"

${ }^{9}$ Termo usado no jargão policial para fazer referência aos ditos bandidos.

${ }^{10}$ Expressão utilizada para designar a atividade informal que visa complementar a renda de um trabalhador.

\section{REFERÊNCIAS}

ABDALA, V. Brasil tem 5\% mais vigilantes privados do que policiais militares. Agência Brasil: EBC - Empresa Brasil de Comunicação. Rio de Janeiro, 3 jun. 2008. Disponível em: <www.agenciabrasil.gov.br/noticias/2008/06/02/ materia.2008-06-02.6503874769>. Acesso em: 5 mar. 2009.

ANDRADE, V. R. Do paradigma etiológico ao paradigma da reação social: mudança e permanência de paradigmas criminológicos na ciência e no senso comum. Revista Seqüência - Estudos Jurídicos e Políticos. Florianópolis, ano 16,

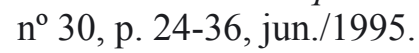

\footnotetext{
ARANTES, E. M. Pensando a Psicologia aplicada à Justiça. In: BRANDÃO, E.; SIGNORINI, H. (Org.). Psicologia Jurídica no Brasil. Rio de Janeiro: NAU, 2004. p. 15-49.
} 
ARGÜELLO, K. et al. Do Estado Social ao Estado Penal: invertendo o discurso da ordem. In: BITTAR, W. B.. (Org.). A Criminologia no século XXI. Rio de Janeiro: Lumen Juris, 2007. p. 119-144. Disponível em: $<$ http://www.cirino.com. br/artigos/Artigo\%20Katie.pdf>. Acesso em: 15 fev. 2009.

BAPTISTA, L. A. A solidão e a inércia dos discursos psi. In: . A cidade dos sábios: reflexões sobre a dinâmica social nas grandes cidades. São Paulo: Summus, 1999. p. 33-44.

BATISTA, V. M. A Nomeação do Mal. In: MENEGAT, M.; NERI, R. (Org.). Criminologia e subjetividade. Rio de Janeiro : Lumen Juris, 2005. p. 41-46.

. O globo da morte. In: BENEVIDES, R.; PASSOS, E.; RAUTER, C. (Org.)

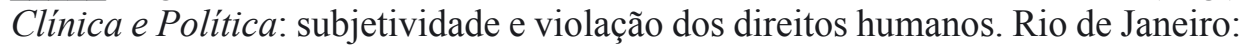
Te Corá, 2002. p. 59-64.

BAUMAN, Z. Em busca da Politica. Rio de Janeiro: J. Zahar, 2000.

BICALHO, P. P. G. Subjetividade e abordagem policial: por uma concepção de direitos humanos onde caibam mais humanos. 2005. Tese (Doutorado)Universidade Federal do Rio de Janeiro, Rio de Janeiro, 2005.

. Ordem para quem? Jornal do Brasil, Rio de Janeiro, ano 118, n. 311, 14 fev. 2009. Caderno Cidade, p. A15.

BRASIL. Constituição (1988). Constituição da República Federativa do Brasil. 4. ed. São Paulo: Saraiva, 2008.

CASTEL, R. A insegurança social: o que é ser protegido? Petrópolis: Vozes, 2005.

COIMBRA, C. M. B. Cidadania ainda recusada: o Plano Nacional de Direitos Humanos e a Lei sobre mortos e desaparecidos políticos. In: CONSELHO FEDERAL DE PSICOLOGIA (Org.). Psicologia, ética e direitos humanos. Brasília: CFP, 1998. p. 91-113.

. Direitos humanos e violência social: a produção do pânico. Niterói, 2001. Disponível em: <http://www.slab.uff.br/exibetexto2.php>. Acesso em: $18 \mathrm{fev}$. 2009.

. Guardiães da Ordem: uma viagem pelas práticas "psi” no Brasil do "Milagre". Niterói: Oficina do Autor, 1995a.

. Produção do Medo e da Insegurança. Niterói, 1995b. Disponível em: $<$ http://www.slab.uff.br/exibetexto2.php $>$. Acesso em: 18 fev. 2009. 
COSTA, A. T. M. Polícia, controle social e democracia. In: Entre a lei e a ordem. Rio de Janeiro: FGV, 2004. cap. 1, p. 35-63.

DELEUZE, G.; PARNET, C. Diálogos. São Paulo: Escuta, 1998.

DORNELLES, J. R W. Conflitos e segurança: entre pombos e falcões. Rio de Janeiro: Lúmen Juris, 2003.

FERREIRA NETO, J. L. Processos de subjetivação e novos arranjos urbanos. Revista do Departamento de Psicologia -UFF, Niterói, v. 16, n. 1, p. 111-120, jan./jun. 2004.

FOUCAULT, M. Microfísica do Poder. Rio de Janeiro: Graal. 2007.

. Vigiar e Punir: História da violência nas prisões. Petrópolis: Vozes, 1997.

GUATTARI, F.; ROLNIK, S. B. Micropolítica: cartografias do desejo. Petrópolis: Vozes, 2007.

KASTRUP, V. A psicologia na rede e os novos intercessores. In: FONSECA, T. G.; FRANCISCO, D. (Org.). Formas de ser e habitar a contemporaneidade. Porto Alegre: UFRGS, 2000. p. 13-26.

MACHADO, R. Introdução: Por uma genealogia do Poder. In: FOUCAULT, M. Microfísica do Poder. Rio de Janeiro: Graal, 2007. p. VII-XXIII.

MUNIZ, J. O. A Crise de identidade das Polícias Militares: Dilemas e Paradoxos da Formação. Security and Defense Studies Review, v. 1, n. 2, p. 187-198, Winter 2001 .

MUNIZ, J.; ZACCHI, J. M. Avanços, frustrações e desafios para uma política progressista, democrática e efetiva de segurança pública no Brasil. In: POLÍTICAS PÚBLICAS DE SEGURIDAD CIUDADANA EN LOS PAÍSES DEL CONO SUR: PROPUESTAS E RECOMENDACIONES, 2004, Santiago do Chile. Anais... Cadernos PROSUR. São Paulo - Santiago : Friedrich Ebert Stiftung, 2004.

RIBEIRO, C.; DIAS, R.; CARVALHO, S. Discursos e práticas na construção de uma política de segurança: o caso do governo Sérgio Cabral Filho (2007-2008). In: JUSTIÇA GLOBAL (Org.). Segurança, Tráfico e Milícias no Rio de Janeiro. Rio de Janeiro: Fundação Heinrich Böll, 2008. p. 6-15

WACQUANT, L. As Prisões da Miséria. Rio de Janeiro: J. Zahar, 2001.

Recebido em: março de 2009 Aceito em: julho de 2009 